\title{
Late visual field changes following cryotherapy for retinopathy of prematurity stage 3
}

Department of Ophthalmology, Center, 49100 Petah Tikva, Israel I Kremer I Nissenkorn M Lusky Y Yassur

Correspondence to: I Kremer, MD.

Accepted for publication 16 November 1994

\author{
I Kremer, I Nissenkorn, M Lusky, Y Yassur
}

\begin{abstract}
Aims-The correlation between cryoscars and visual field defects following cryoablation was studied.

Methods-A Humphrey 120 full field screening test was performed in 10 children (15 eyes) who were treated by cryotherapy between 10 and 14 years previously for retinopathy of prematurity (ROP) stage 3.

Results-In eight eyes treated by cryoablation through $360^{\circ}$ in zone I or II, a moderate circumferential peripheral visual field constriction was found. In seven other eyes, cryotreated up to $180^{\circ}$ only in the temporal retina (zone III), a nasal field constriction was noted. There was no evidence of late development of retinal tears or retinal detachment. The correlation between the primary cryoapplications, late chorioretinal cryoscars, and the visual field changes was evaluated.
\end{abstract}

Conclusion-Late chorioretinal scars following cryotherapy for ROP stage 3 are associated with visual field defects, but as these defects are at the periphery of the visual field they do not cause any subjective derangements 10-14 years after treatment.

(Br f Ophthalmol 1995; 79: 267-269)

Cryotherapy has been used to treat retinopathy of prematurity (ROP) stage 3 since the early 1970s, first in Japan ${ }^{1-4}$ and later in other countries. ${ }^{5-18}$ The method has changed from a direct freezing technique, which consisted of cryoablation of the ridge itself and the neovascular fronds posterior to it, ${ }^{5-10}$ to an indirect technique whereby cryotherapy is applied to the avascular retina only, avoiding

Table 1 Patient data ${ }^{\star}$

\begin{tabular}{|c|c|c|c|c|c|}
\hline \multirow{2}{*}{$\begin{array}{l}\text { Patient } \\
\text { No }\end{array}$} & \multirow{2}{*}{$\begin{array}{l}\text { Aget } \\
\text { (years) }\end{array}$} & \multicolumn{2}{|c|}{ Visual acuity $\ddagger$} & \multicolumn{2}{|c|}{ Refraction (SES) } \\
\hline & & $R E$ & $L E$ & $R E$ & $L E$ \\
\hline 1 & 13 & $6 / 9$ & $6 / 9$ & $-1 \cdot 0$ & -0.50 \\
\hline 2 & 14 & $6 / 6$ & $6 / 6$ & -0.5 & $-1 \cdot 0$ \\
\hline 3 & 12 & $6 / 20$ & $6 / 12$ & $-11 \cdot 0$ & $-5 \cdot 0$ \\
\hline 4 & 14 & $6 / 9$ & $6 / 6$ & $-3 \cdot 0$ & $-2 \cdot 0$ \\
\hline 5 & 13 & $6 / 7 \cdot 5$ & $6 / 7 \cdot 5$ & -3.5 & $-3 \cdot 5$ \\
\hline 6 & 10 & $6 / 12$ & $6 / 9$ & -0.75 & $-2 \cdot 0$ \\
\hline 7 & 10 & $6 / 12$ & $6 / 9$ & $-10 \cdot 0$ & $-7 \cdot 0$ \\
\hline 8 & 12 & $6 / 6$ & $6 / 6$ & -0.5 & $-12 \cdot 0$ \\
\hline 9 & 14 & $6 / 9$ & $6 / 7 \cdot 5$ & -1.5 & -1.0 \\
\hline 10 & 11 & $6 / 6$ & $6 / 12$ & -1.25 & $-1 \cdot 0$ \\
\hline
\end{tabular}

*The best corrected visual acuity and final refraction

performed 10 to 14 years after cryotherapy for active ROP

disease. The age of each child at the optometric and the visual

field examination is also presented.

tAt visual acuity and visual field testing.

¥Best corrected visual acuity.

§spherical equivalent. the ridge itself. ${ }^{11-18}$ Since 1976 we have been using cryotherapy for the treatment of ROP stage 3 according to a protocol published previously. ${ }^{11} 18$ In the present study, we report the long term visual field changes in children who underwent this procedure between 10 and 14 years previously.

\section{Patients and methods}

The study included 10 children ( 15 eyes) with a clinical history of ROP stage 3 (moderate) with confluent disease of more than 3.5 clock hours who were treated by cryotherapy 10-14 years previously. All underwent cryoablation of the avascular retina anterior to both the ridge and the fibrovascular proliferations. The freezing zone did not include the ridge itself, and the cryoapplications covered only the avascular retina up to the ora serrata, in accordance with our protocol. ${ }^{11} 18$ The children were followed periodically during the following years by visual acuity examination, refraction, orthoptic evaluation, and funduscopy. The best corrected visual acuity was evaluated by the Snellen visual acuity chart when the children were 10 years old or more. At the same time, visual field testing was also performed using the Humphrey automatic perimeter with the 120 full field screening program. For eyes with myopia higher than $-5 \cdot 0$ dioptres, a soft contact lens (Acuvue, Johnson \& Johnson Company, USA) was fitted for the visual field test. In addition, each child underwent wide angle funduscopic photography with a Nikon fundus camera and was questioned regarding any disturbances in his field of vision and night vision. Each fundus photograph was compared with the visual field findings. The correlation between the primary cryotherapy, the late chorioretinal cryoscars, and final visual field defects was evaluated with respect to location and extent.

It should be pointed out that the physical and mental status of all 10 children were evaluated by a paediatrician and found to be within the normal range.

\section{Results}

All the pre- and post-treatment data of the 10 children (15 eyes) are presented in Tables 1 and 2 . The age of the children at the optometric and visual field examination ranged between 10 and 14 years, with an average of 12.3 years. The best corrected visual acuity in 14 eyes of nine children ranged between $6 / 6$ and $6 / 12$; in one eye (patient no 3 ) the visual acuity was $6 / 20$ (Table 1 ). The refractive error of 14 eyes ranged between -1.0 and -11.0 
Table 2 Correlation between cryotherapy and late visual field defect ${ }^{\star}$

\begin{tabular}{|c|c|c|c|c|c|c|}
\hline \multirow{2}{*}{$\begin{array}{l}\text { Patient } \\
\text { no }\end{array}$} & \multicolumn{2}{|c|}{ Primary cryotherapy (clock hours) } & \multicolumn{2}{|c|}{ Visual field defect (degrees) } & \multicolumn{2}{|c|}{ Late chorioretinal scars } \\
\hline & $R E$ zone & LE zone & $R E$ & $L E$ & $R E$ & $L E$ \\
\hline $\begin{array}{r}1 \\
2 \\
3 \\
4 \\
5 \\
6 \\
7 \\
8 \\
9 \\
10\end{array}$ & $\begin{array}{l}\text { III: } 12-6 \\
\text { Not treated } \\
\text { II: } 12-12 \\
\text { I: } 12-12 \\
\text { Not treated } \\
\text { Not treated } \\
\text { II: } 12-12 \\
\text { III: } 12-6 \\
\text { I: } 12-12 \\
\text { Not treated }\end{array}$ & $\begin{array}{l}\text { Not treated } \\
\text { III: } 12-6 \\
\text { II: } 12-12 \\
\text { I: } 12-12 \\
\text { III: } 2-6 \\
\text { III: } 1-6 \\
\text { II: } 12-12 \\
\text { III: } 1-6 \\
\text { I: } 12-12 \\
\text { III: } 12-5\end{array}$ & $\begin{array}{l}20 \mathrm{~N} \\
\text { Normal } \\
20 \mathrm{~N} \text { and } 15 \mathrm{~T} \\
25 \mathrm{~N} \text { and } 20 \mathrm{~T} \\
\text { Normal } \\
\text { Normal } \\
25 \mathrm{~N} \text { and } 20 \mathrm{~T} \\
20 \mathrm{~N} \\
30 \mathrm{~N} \text { and } 20 \mathrm{~T} \\
\text { Normal }\end{array}$ & $\begin{array}{l}\text { Normal } \\
15 \mathrm{~N} \\
15 \mathrm{~N} \text { and } 20 \mathrm{~T} \\
25 \mathrm{~N} \text { and } 20 \mathrm{~T} \\
15 \mathrm{~N} \\
15 \mathrm{~N} \\
20 \mathrm{~N} \text { and } 15 \mathrm{~T} \\
15 \mathrm{~N} \text {. } \\
25 \mathrm{~N} \text { and } 20 \mathrm{~T} \\
10 \mathrm{~N}\end{array}$ & $\begin{array}{l}6 \mathrm{H}-\mathrm{TP} \\
\text { None } \\
12 \mathrm{H}-\mathrm{P} \\
12 \mathrm{H}-\mathrm{MP} \\
\text { None } \\
\text { None } \\
12 \mathrm{H}-\mathrm{P} \\
6 \mathrm{H}-\mathrm{TP} \\
12 \mathrm{H}-\mathrm{MP} \\
\text { None }\end{array}$ & $\begin{array}{l}\text { None } \\
6 \mathrm{H}-\mathrm{TP} \\
12 \mathrm{H}-\mathrm{P} \\
12 \mathrm{H}-\mathrm{MP} \\
4 \mathrm{H}-\mathrm{TP} \\
5 \mathrm{H}-\mathrm{TP} \\
12 \mathrm{H}-\mathrm{P} \\
5 \mathrm{H}-\mathrm{TP} \\
12 \mathrm{H}-\mathrm{MP} \\
5 \mathrm{H}-\mathrm{TP}\end{array}$ \\
\hline
\end{tabular}

$\mathrm{N}=$ nasal; $\mathrm{T}=$ temporal; $\mathrm{RE}=$ right eye; $\mathrm{LE}=$ left eye; $\mathrm{TP}=$ temporal periphery; $\mathrm{MP}=$ mid periphery; $\mathrm{P}=$ periphery $\left(360^{\circ}\right) ; \mathrm{H}=\mathrm{clock}$ hours (total).

*The correlation between the extent and zone location of the cryotherapy performed at diagnosis of the active disease, the extent and fundus location of the late chorioretinal atrophic cryotherapy scars, and the visual field defects. The extent of therapy is expressed in clock hours; $12-12$ is 360 degrees. Zone of active disease is expressed in Roman numerals. The visual fields were evaluated by the Humphrey 120 screening program at 10-14 years of age and are expressed as degrees of temporal or nasal field constriction. For myopia over $-5 \cdot 0$ dioptres a soft contact lens was fitted for the visual field testing.

dioptres (spherical equivalent). Only one eye (patient no 6) was found to be emmetropic (Table 1). The funduscopic findings were as follows (Table 2).

Group $A$ Eight eyes with $360^{\circ}$ confluent pigmented atrophic chorioretinal scars located nasally in the retinal periphery, posterior to the ora serrata and from the mid periphery to the ora serrata on the temporal side;

Group $B$ Seven eyes showing up to $180^{\circ}$ confluent pigmented chorioretinal atrophic scars in the temporal retina, extending from the mid periphery to the ora serrata (Fig 1).

There was no evidence of late development of retinal tears or retinal detachment in any of the children during follow up, and none required additional surgical intervention.

The visual field evaluation in the eight eyes in which the cryoscars were found through $360^{\circ}$ (group A) demonstrated a circumferential peripheral field constriction of $10-20^{\circ}$ temporally and $20-30^{\circ}$ nasally. In the seven eyes in which the cryoscars were found through $180^{\circ}$ in the temporal retinal periphery only (group B) (Fig 1), a nasal visual field constriction of $10-20^{\circ}$ was found (Fig 2). It should be pointed out that none of the children complained of visual field disturbances, even following specific questions. None had problems with night vision.

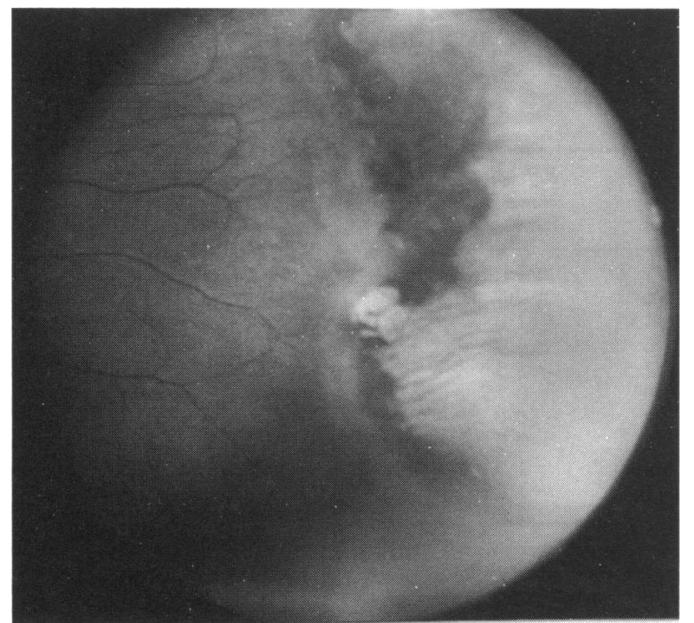

Figure 1 Photographic appearance of peripheral temporal pigmented chorioretinal scars 10 years after cryotreatment of the right eye of patient 1.

\section{Discussion}

The recent preliminary results of the Multicenter Trial of Cryotherapy (MTC) for $\mathrm{ROP}^{17}$ support the efficacy of cryotherapy in reducing by approximately $50 \%$ the risk of unfavourable retinal outcome for ROP stage 3, defined as 'threshold' disease. The method employed in the MTC study was that described by Nagata $e t a l^{4}$ and Majima et $a l^{2}$ and consisted of ablation of the avascular retina anterior to the ridge. The appearance of the avascular zone immediately following the cryoprobe applications is illustrated diagrammatically in the report of this study. ${ }^{17}$ In that diagram, the spacing of the freeze spots and their relation to the ora serrata and the fibrovascular ridge are clearly pointed out.

In 1980 , Ben-Sira et al ${ }^{11}$ reported their technique of transcleral cryotherapy which involved cryoablation of the avascular retina anterior to the ridge and avoided direct treatment of the ridge itself and the neovascular growths posterior to it. Later, Nissenkorn et $a l^{12}$ reported a clinicopathological case of almost complete regression of the neovascular disease in the retinal areas posterior to the cryoscars and low grade, active neovascular disease between the scars. The histopathological examination of the cryoscars showed complete destruction of all retinal layers and the choroid as well. Both the retina and choroid were replaced by pigmented gliotic scarred tissue. Therefore, peripheral visual field changes are expected following cryotherapy for ROP. In the present study, we employed our previously reported method of cryoablation, which covered the whole avascular retina anterior to the ridge. ${ }^{11} 1218$

In an attempt to find an analogy between the effect of cryotherapy on the visual field and night vision in ROP children and the effect of panretinal photocoagulation (PRP) on the visual field and night vision of diabetics, it is interesting to note that the Diabetic Retinopathy Study Research Group ${ }^{19}$ found that $25 \%$ of xenon treated eyes suffered modest constriction of the visual field and an additional $25 \%$ had more severe constriction. Only $5 \%$ of the eyes treated with the argon laser showed some constriction of the visual field to the large test object used (Goldmann IVe 4). 


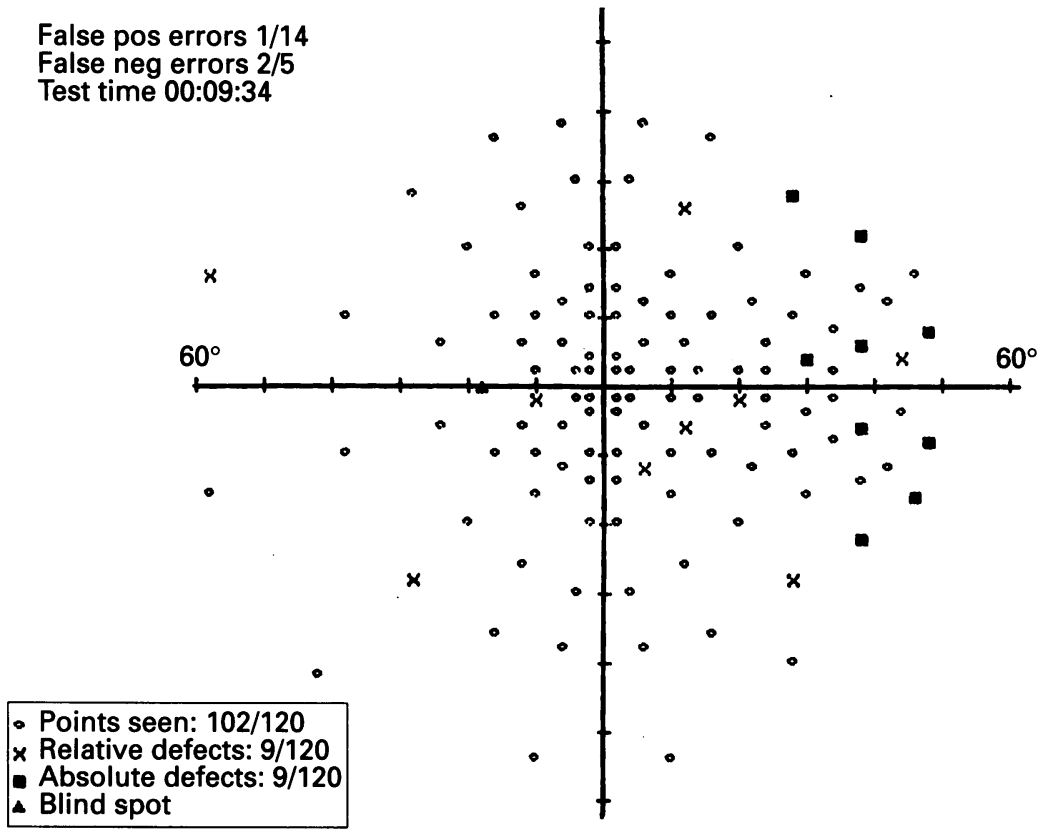

Figure 2 Humphrey screening visual field of the right eye of patient no 1, showing a nasal field constriction of approximately $20^{\circ}$ on the horizontal line.

Pender $e t a l^{20}$ studied the effect of PRP on dark adaptation of diabetics with proliferative retinopathy and found further deterioration of dark adaptation after PRP. Although they could find no reason for the abnormal dark adaptation of untreated control diabetic patients, they suggested retinal hypoxia, oedema, or electrolyte imbalance as pathogenic factors. PRP probably contributes to this abnormality by decreasing the number of available rods and disrupting the intraretinal integration circuits.

Peripheral retinal ischaemia caused by incomplete and abnormal vascularisation is also present in ROP. ${ }^{2122}$ This factor, together with the peripheral retinal thinning and degeneration found in association with regressed ROP without cryotherapy, ${ }^{22}{ }^{23}$ may contribute by itself to visual field constriction. Cryotherapy of the entire ischaemic retinal area probably plays a role in visual field constriction via the same mechanism as PRP - that is, by decreasing the number of rods and disrupting the intraretinal integration circuits.

Finally, it should be pointed out that some ROP patients followed for many years may eventually lose vision for no obvious reason. Tasman and Brown ${ }^{24}$ reported on two monocular ROP patients who gradually lost vision. Only one developed late rhegmatogenous retinal detachment which was treated surgically. In the other patient, progressive retinal pigment epithelial alterations were noted by fluorescein angiography. In both patients, the visual field constricted gradually to a small central island. These authors speculated that the deterioration in visual function occurred as a result of retinal pigment epithelial loss in association with compromised photoreceptors.

The correlation between the cryoscars and visual field defects following cryoablation was studied in our work. The visual field and acuity findings are reliable, as they were performed at the age of 10 years or more in children of normal mental status. It can be seen in Figures 1 and 2 that the location and extent of the visual field defects correlate well with that of the cryoscars, as evaluated by the fundus photographs.

We conclude from our data that the late chorioretinal scars following cryotherapy for ROP stage 3 are indeed associated with peripheral visual field defects. As these defects are confined to the periphery of the visual field, they do not cause any subjective derangements 10 to 14 years after treatment. Longer follow up is necessary to identify any possible further deterioration in visual function.

1 Yamashita Y. Studies on retinopathy of prematurity: III Cryocautery for retinopathy of prematurity. $f_{p n} \mathcal{F}$ Clin Ophthalmol 1972; 26: 385-93.

2 Majima A, Takahashi M, Hibino Y. Clinical observations of photocoagulation on retinopathy of prematurity. Ipn f Clin Ophthalmol 1976; 30: 93-7.

3 Sasaki K, Yamashita Y, Maekawa T, Adachi T. Treatment of retinopathy of prematurity in active stage by cryocautery. Ipn $\mathcal{f}$ Ophthalmol 1976; 20: 384-95.

4 Nagata $M$, Yamagishi N, Ikeda S. Summarized results of the treatment of acute proliferative retinopathy of prematurity during the past 15 years in Tenri Hospital. Acta Soc Ophthalmol fpn 1982; 86: 1236-44.

5 Payne J, Patz A. Treatment of acute retrolental fibroplasia. Trans Am Acad Ophthalmol 1972; 76: 1234-46.

6 Harris GS. Retinopathy of prematurity and retinal detachment. Can 7 Ophthalmol 1976; 11: 21-95.

7 McCormick AQ. Retinopathy of prematurity. Curr Probl Pediatr 1977; 7: 11-3.

8 Kingham JO. Acute retrolental fibroplasis II. Treatment by cryosurgery. Arch Ophthalmol 1978; 96: 2049-53.

9 Hindle NW, Leyton J. Prevention of cicatricial retrolental fibroplasia by cryotherapy. Can $\mathcal{f}$ Ophthalmol 1978; 13: 277-82.

10 Keith CG. Visual outcome and effect of treatment in stage III developing retrolental fibroplasia. $\mathrm{Br} \mathcal{F}$ Ophthalmol 1982; 66: 446-9.

11 Ben-Sira I, Nissenkorn I, Grunwald E, Yassur Y Treatment of acute retrolental fibroplasia by cryopexy. Br $₹$ Ophthalmol 1980; 64: 758-62.

12 Nissenkorn I, Kremer I, Ben-Sira I, Cohen S, Garner A. A clinicopathological case of retinopathy of prematurity (ROP) treated by peripheral cryopexy. $\mathrm{Br} \mathcal{F}$ Ophthalmo 1984; 68: $36-41$.

13 Topilow HW, Ackerman AL, Wang FM. The treatment of advanced retinopathy of prematurity by cryotherapy and scleral buckling surgery. Ophthalmology 1985; 92 379-87.

14 Mousel DK. Cryotherapy for retinopathy of prematurity. Ophthalmology 1985; 92: 375-8.

15 Tasman W. Management of prematurity. Ophthalmology 1985; 92: 995-9.

16 Tasman W, Brown GC, Schaffer DB, Quinn G, Naidoff $M$ Benson WE, et al. Cryotherapy for active retinopathy of prematurity. Ophthalmology 1986; 93: 580-5.

17 Multicenter Trial of Cryotherapy for Retinopathy of Prematurity. Preliminary results. Arch Ophthalmol 1988, 106: 471-8.

18 Ben-Sira I, Nissenkorn I. Treatment of retinopathy of prematurity with cryotherapy. The Beilinson Experience. In McPherson AR, Hittner HM, Kretzer, eds. Retinopathy of prematurity. Toronto, Philadelphia: BC Decker, 1986: 129-71.

19 The Diabetic Retinopathy Study Research Group. Photocoagulation treatment of proliferative diabetic retinopathy - clinical application of diabetic retinopathy retinopathy - clinical application of diabetic retinopathy
study (DRS). Findings, DRS Report No 8. Ophthalmology study (DRS). Findings

20 Pender PM, Benson WE, Compton H, Cox GB. The effects of panretinal photocoagulation on dark adaptation in diabetics with proliferative retinopathy. Ophthalmology 1981; 88: 635-8.

21 Cogan DG. Development of senescence of the human vasculature: Doyne Memorial Lecture, 1963. Tran Ophthalmol Soc 1963; 83: 465-89.

22 Ben-Sira I, Nissenkorn I, Kremer I. Retinopathy of prematurity. Major review. Surv Ophthalmol 1988; 33: 1-16.

23 Tasman WS. Late complications of retrolental fibroplasia. Ophthalmology 1979; 86: 1724-40.

24 Tasman WS, Brown GC. Progressive visual loss in adults with retinopathy of prematurity (ROP). Trans Am with retinopathy of prematurity
Ophthalmol Soc 1988; 86: 367-72. 